\title{
ANALISIS TINGKAT PARTISIPASI DAN PERSEPSI ANGGOTA AFINITAS (KELOMPOK DAHLIA SEJAHTERA) TERHADAP PROGRAM DESA MANDIRI PANGAN
}

(Studi Kasus Kelurahan Padang Serai Kecamatan Kampung Melayu Kota Bengkulu)

\section{ANALYSIS OF PARTICIPATION LEVEL AND PERCEPTION OF AFINITY MEMBERS (DAHLIA SEJAHTERA GROUP) OF THE VILLAGE FOOD RESILIENCE PROGRAM}

(Case Study of Padang Serai Sub-District, Kampung Melayu District, Bengkulu City)

\author{
Nuzula1), Ana Nurmalia'), Mujiono') \\ 1) Proram Studi Agribisnis, Fakultas Pertanian, Universitas Dehasen Bengkulu \\ Email : anurmalia@rocketmail.com
}

\begin{abstract}
ABSTRAK
Penelitian untuk menganalisis tingkat partisipasi dan persepsi anggota kelompok afinitas (dahlia sejahtera) terhadap Program Desa Mandiri Pangan di Desa Padang Serai, Kabupaten Kampung Melayu, Kota Bengkulu. Penelitian ini dilakukan secara sengaja. Data yang digunakan dalam penelitian ini adalah data primer dan data sekunder. Data primer diperoleh dari hasil wawancara langsung dengan petani yang digunakan sebagai responden dengan menggunakan kuesioner (kuesioner) dan dianalisis secara deskriptif menggunakan tabulasi dan deskripsi verbal. Sampel dalam penelitian ini ditentukan oleh 32 responden, yaitu semua anggota kelompok afinitas yang ditemukan di Desa Padang Serai, Kabupaten Kampung Melayu. Tingkat partisipasi dalam Program Desa Mandiri Pangan memiliki ratarata 28,13 yang berarti dalam kategori sedang dan untuk tingkat persepsi responden rata-rata 33,06. Kondisi ini menunjukkan bahwa anggota kelompok afinitas (dahlia makmur) memiliki persepsi yang tinggi atau baik terhadap Program Desa Mandiri Pangan (DMP) di Desa Padang Serai, Kabupaten Kampung Melayu, Kota Bengkulu.
\end{abstract}

Kata Kunci : Tingkat Partisipasi, Persepsi, Program Desa Mandiri Pangan.

\section{ABSTRACT}

The research to analyze the level of participation and perception of affinity group members (dahlia sejahtera) towards the Food Independent Village Program in Padang Serai Village, Kampung Melayu District, Bengkulu City. The study was conducted purposively. The data used in this study are primary data and secondary data. Primary data were obtained from the results of direct interviews with the farmers who were used as respondents by using a questionnaire (questionnaire) and analyzed descriptively using tabulations and verbal descriptions. The sample in this study was determined by 32 respondents, namely all members of the affinity group found in the Padang Serai Village, Kampung Melayu District. The level of participation in the Food Independent Village Program has an average of 28.13 which means in the medium category and for the perceptual level of respondents at an average of 33.06. This condition indicates that affinity group members (dahlia prosperous) have a high or good perception of the Food Independent Village Program (DMP) in Padang Serai Village, Kampung Melayu District, Bengkulu City.

Keywords: Participation Rate, Perception, Food Independent Village Program. 


\section{PENDAHULUAN}

Program Desa Mandiri Pangan (Demapan) merupakan program aksi yang dilaksanakan oleh Kementerian Pertanian dengan tujuan untuk mengurangi rawan pangan dan gizi melalui pendayagunaan sumber daya, kelembagaan dan kearifan lokal perdesaan. Untuk tercapainya tujuan Demapan program dirancang dalam kurun waktu 4 tahun, melalui 4 tahapan yaitu : (i) tahap persiapan, meliputi seleksi desa rawan pangan dan pembentukan kelompok KK miskin ; (ii) tahap penumbuhan, mulai adanya usaha produktif, pembentukan Lembaga Keuangan Desa (LKD), berfungsinya posyandu dan bekerjanya sistem ketahanan pangan dari aspek ketersediaan, distribusi dan konsumsi serta koordinasi program lintas sektor untuk pembangunan sarana prasarana wilayah perdesaan, (iii) tahap pengembangan, adanya perkembangan ekonomi produktif, peningkatan modal LKD, pengembangan sistem ketahanan pangan ; (iv) tahap kemandirian, adanya peningkatan dinamika kelompok dan usaha ekonomi produktif, adanya jaringan kemitraan, berfungsinya LKD sebagai layanan modal dan berfungsinya Tim Pangan Desa (TPD) dalam mengkoordinasikan program lintas sektoral (Darwis, 2012).

Penumbuhan LKD dimaksudkan untuk mempersiapkan embrio lembaga yang mengelola keuangan di perdesaan.

LKD ditumbuhkan oleh perwakilan kelompok-kelompok afinitas yang berfungsi untuk mengelola dana Bansos, simpanan modal/tabungan masyarakat, dan layanan permodalan kepada RTM khususnya dan masyarakat desa umumnya untuk pengembangan usaha produktif. Kepengurusan LKD dipilih oleh masyarakat desa, dan atau perwakilan dari KA dengan kriteria mampu mengelola keuangan dan usaha serta dipercaya oleh masyarakat. LKD di desa mandiri pangan merupakan hasil akhir dari kegiatan dan lembaga ini diharapkan bisa mengelola keuangan KA maupun gapoktan. Tetapi dalam pelaksanaannya belum sepenuhnya program Demapan yang masuk tahap kemandirian sudah mendirikan LKD dan masih mempercayakan pengelolaan keuangan di dalam kelompok (Darwis dan Rusastra, 2011).

Badan Pusat Statistik merilis angka kemiskinan Provinsi Bengkulu, Pada September 2016 angka kemiskinan dicatat mencapai 325.600 jiwa atau 17,03 persen dari jumlah penduduk, Sementara di September 2017, jumlah warga miskin kini berada pada 302.620 jiwa atau tinggal sebesar 15,59 persen lagi. Bengkulu pun menjadi satu dari delapan provinsi dengan penurunan kemiskinan tertinggi di Indonesia. (BPS,2017) 
Sasaran utama penerima manfaat adalah rumah tangga miskin di desa rawan pangan. Rumah tangga miskin ini dihimpun dalam suatu wadah, disebut dengan kelompok afinitas, yang diikat dengan rasa kesatuan dan kebersamaan oleh jaringan persahabatan sehingga memungkinkan mereka mampu untuk melaksanakan kegiatan tertentu secara bersama. Guna mendukung kegiatan kelompok afinitas maka disediakan bantuan sosial oleh pemerintah serta pembinaan secara rutin oleh petugas pendamping (Deptan, 2012).

Salah satu upaya menanggulangi masalah kemiskinan dan kerawanan pangan, pemerintah melalui Badan Ketahanan Pangan Departemen Perrtanian, pada tahun 2006 telah mengembankan Program Desa Mandiri Pangan. Desa Mandiri Pangan adalah desa yang masyarakatnya mempunyai kemampuan untuk mewujudkan ketahanan pangan dan gizi melalui pengembangan subsistem ketersediaan, subsistem distribusi dan subsistem konsumsi dengan memanfaatkan sumberdaya setempat secara berkelanjutan. Pengembangan desa mandiri pangan bertujuan untuk meningkatkan kemandirian pangan, meningkatkan peran dan fungsi kelembagaan masyarakat desa, mengembangakan sistem ketahanan pangan masyarakat desa, meningkatkan pendapatan masyarakat dan meningkatkan asesibilitas masyarakat, dengan sasaran utama rumah tangga miskin di Desa rawan pangan (BKP, 2014).

Di Provinsi Bengkulu beberapa tahun belakangan (2006-2015) Departemen Pertanian mengembangkan Desa Mandiri Pangan, dan pada tahun 2015 telah ada untuk menambah areal Desa mandiri Pangan itu, khususnya di kabupaten yang sebelumnya belum tersentuh. Pada tahun sebelumnya pengembangan Desa Mandiri Pangan di Kabupaten Rejang Lebong, Bengkulu Utara, Bengkulu Selatan dan Kepahiang. Untuk mendukung kegiatan tersebut Departemen Pertanian memberikan kucuran dana sebesar $\mathrm{Rp}$ 1,98 miliar. Bantuan itu diberikan pada Kabupaten Rejang Lebong, Bengkulu Selatan dan Bengkulu Utara masing-masing Rp 515 juta dan Kabupaten Kepahiang sebesar Rp 435 juta. Jumlah desa yang dikembangkan berjumlah 14 desa, yang selama ini dikenal sebagai desa-desa rawan kekurangan pangan (BKP, 2014).

Keberhasilan Program Desa Mandiri Pangan sangat tergantung dari sejauh mana partisipasi dan persepsi masyarakat serta pendekatan yang dilakukan oleh pemerintah kepada masyarakat dalam tahap perencanaan, pelaksanaan, monitoring dan evaluasi. 
Suatu program sering mengalami kegagalan karena tidak sesuai keinginan masyarakat. Hal ini terjadi karena kegiatan yang dilakukan sering kali menggunakan pendekatan dari atas sehingga keinginan dari masyarakat kurang disalurkan dan berakibat pada partisipasi dan persepsi yang bersifat pasif. Untuk mengantisipasi agar program tersebut berjalan, yang diperlukan adalah pendekatan dari bawah, sehingga semua aspirasi masyarakat relatif diakomodaskan dan berimbas pada partisipasi aktif dari masyarakat dalam semua kegiatan yang akan dilakukan. Pendekatan ini menjanjikan keberhasilan kegiatan yang akan dilaksanakan karena kegiatan tersebut mencerminkan keinginan masyarakat pada umumnya (Iswantoro, 2006).

Untuk pelaksanaan Program Desa Mandiri Pangan di Kelurahan Padang Serai Kecamatan Kampung Melayu Kota Bengkulu dilakukan melalui kelompok afinitas yang di dampingi penyuluh pendamping. Penyaluran dana program desa mandiri pangan di Kelurahan Padang Serai Kecamatan Kampung Melayu Kota Bengkulu, dikirim melalui rekening kelompok afinitas dengan jumlah sebesar Rp 100.000.000 kemudian setelah dana itu cair pengurus dan anggota kelompok afinitas mengadakan rapat musyawarah untuk memanfaatkan dana $\mathrm{Rp}$ 100.000.000 tersebut. Setiap anggota mendapatkan dana secara adil sesuai dengan kebutuhan yang diajukan.

Kelurahan Padang Serai

Kecamatan Kampung Melayu Kota Bengkulu merupakan kelurahan yang memiliki kategori mandiri pangan yang tinggi di banding kelurahan atau Desa lain yang ada di Kota Bengkulu berdasarkan indikator subsistem ketersediaan, subsistem distribusi dan subsistem konsumsi dapat dilihat dari tabel 1 .

Berhasil tidaknya pelaksanaan kegiatan program ini di tiap tingkat desa sangat ditentukan oleh partisipasi dan persepsi masyarakat dalam semua aktifitas program. Tanpa adanya partisipasi dan persepsi yang tinggi dari masyarakat maka kegiatan yang sudah dirancang sedemikian rupa dapat berjalan sesuai dengan yang diharapkan dan tujuan dari pelaksanaan program tersebut. Partisipasi dan persepsi anggota dilihat dari perencanaan hingga pelaksanaan, hal ini salah satunya penilaian dalam memanfaatkan keberadaan Program Desa Mandiri Pangan. 
Tabel 1.Kemandirian Sistem Ketahanan Pangan

\begin{tabular}{|l|l|l|l|l|}
\hline \multirow{2}{*}{ No } & \multirow{2}{*}{ Indikator } & \multicolumn{2}{|l|}{ Nilai Skor } \\
\cline { 3 - 5 } & & $\begin{array}{l}\text { Teluk } \\
\text { Sepang }\end{array}$ & $\begin{array}{l}\text { Muara } \\
\text { Bangkahulu }\end{array}$ & $\begin{array}{l}\text { Padang } \\
\text { Serai }\end{array}$ \\
\hline 1 & Sub Sistem Ketersediaan & 32 & 42 & 43 \\
\hline 2 & Sub Sistem Distribusi & 42 & 43 & 47 \\
\hline 3 & Sub Sistem Konsumsi & 40 & 47 & 52 \\
\hline Sub Total & $\mathbf{1 1 4}$ & $\mathbf{1 3 2}$ & $\mathbf{1 4 2}$ \\
\hline \multicolumn{2}{|l}{ Klasisifikasi (KR, KS, KT) } & KS & KS & KT \\
\hline
\end{tabular}

$\mathrm{KR}=$ Klasifikasi Rendah $<80$

KS=Klasifikasi Sedang 80-140

$\mathrm{KT}=$ Klasifikasi Tinggi $>140$

Sumber : BKP Provinsi Bengkulu, 2015

Berdasarkan uraian latar belakang tersebut, maka perlu dilakukan kajian lebih mendalam tentang "Analisis Tingkat Partisipasi dan Persepsi Anggota Afinitas (Dahlia Sejahtera) terhadap Program Desa Mandiri Pangan (Studi Kasus Kelurahan Padang Serai Kecamatan Kampung Melayu Kota Bengkulu)".

\section{METODE PENELITIAN}

Penelitian dilakukan secara sengaja (purposive) yang berada pada Kelurahan Padang Serai Kecamatan Kampung Melayu Kota Bengkulu, dengan pertimbangan bahwa pada kelurahan ini telah menjadi salah satu desa/kelurahan yang mendapat program desa mandiri pangan. Data yang digunakan dalam penelitian ini adalah data primer dan data sekunder. Data primer diperoleh dari hasil wawancara langsung dengan para petani yang dijadikan responden dengan menggunakan daftar pertanyaan (kuisioner). Data sekunder diperoleh dari data yang sudah ada sebelumnya. Data ini akan diperoleh dari kantor-kantor dan instansi yang erat kaitannya dengan penelitian ini yaitu Profil Desa/Kelurahan, Badan Ketahanan Pangan dan Dinas Pertanian. Menurut Arikunto (2006) jumlah populasinya lebih kecil yaitu kurang dari 100 orang maka lebih baik diambil semua sehingga penelitiannya merupakan penelitian populasi sehingga Sampel dalam penelitian ini ditentukan sebesar 32 responden yaitu semua anggota kelompok afinitas yang terdapat pada Kelurahan Padang Serai Kecamatan 
Kampung Melayu Kota. Untuk mengetahui tingkat partisipasi anggota afinitas program desa mandiri pangan dan mengetahui persepsi anggota afinitas program desa mandiri pangan menggunakan analisis deskriptif dengan menggunakan tabulasi dan uraian verbal. Menurut Siegel (2001), metode deskriptif adalah suatu metode dalam penelitian suatu objek, suatu kelompok manusia, kondisi suatu sistem pemikiran ataupun suatu kelas peristiwa pada masa sekarang dengan tujuan untuk membuat gambaran atau lukisan secara sistematis, faktual dan akurat mengenai fakta-fakta serta hubungan antar fenomena yang diselidiki. Parameter ini akan digambarkan oleh beberapa pertanyaan dengan tiga alternatif jawaban. Jawaban yang diberikan berdasarkan tingkatannya dimana: untuk jawaban (setuju $=\mathrm{S}$, kadang-kadang $=\mathrm{KD}$, dan tidak setuju $=$ TS). Alternatif jawaban akan diberi nilai berdasarkan tingkatan (score) $\mathrm{S}=3, \mathrm{KD}=2$, dan $\mathrm{TS}=1$. Rentang nilai (range) masing-masing kategori dapat diketahui dengan menggunakan rumus sebagi berikut:

$\begin{aligned} \text { Interval } & =\frac{\text { nilai atas }- \text { nilai bawah }}{\text { Jumlah Kelas }} \\ \text { Interval } & =\frac{42-14}{3} \\ & =9,3\end{aligned}$

Dimana :

a. nilai atas $=$ skor tertinggi (3) $\mathrm{x}$ Jumlah pertanyaaan

b. nilai bawah = skor terendah (1) $\mathrm{x}$ Jumlah pertanyaan

Kategori :
a. $\quad$ Rendah $=14-23,4$
b. $\quad$ Sedang $=23,4-32,7$
c. Tinggi $=32,7-42$

\section{HASIL DAN PEMBAHASAN}

Tingkat Partisipasi Anggota Afinitas Program Desa Mandiri Pangan

Partisipasi masyarakat Kelurahan Padang Serai Kecamatan Kampung Melayu Kota Bengkulu disajikan pada dasarnya memberikan tanggapan yang berkaitan dengan kegiatan program desa mandiri pangan yang merupakan substansi dari program desa mandiri pangan terkait dengan kondiri Kelurahan Padang Serai yang merupakan desa rawan pangan. Pelaksanaan program desa mandiri pangan dilaksanakan untuk dapat memperbaiki kondisi masalah rawan pangan dan meningkatkan kesejahteraan masyarakat setempat dalam rangka peningkatan kualitas kehidupannya. Program-program/kegiatan tersebut memerlukan dukungan berbagai pihak baik dari pemerintah terutama masyarakat setempat. Dukungan dari masyarakat 
setempat tersebut berupa partisipasi masyarakat terhadap pelaksanaan kegiatan program desa mandiri pangan.

Berdasarkan observasi dan wawancara langsung kepada masyarakat terkait partisipasi masyarakat. Tingkat partisipasi anggota kelompok afinitas (dahlia sejahtera) Program Desa Mandiri Pangan (DMP) di Kelurahan Padang Serai Kecamatan Kampung Melayu Kota Bengkulu disajikan pada tabel disajikan pada tabel 2 .

Pada Tabel 2 menunjukkan tingkat partisipasi Program Desa Mandiri Pangan (DMP) di Kelurahan Padang Serai Kecamatan Kampung Melayu Kota Bengkulu memiliki kisaran dengan skor antara 23,7 sampai 32,75. Berdasarkan hasil penelitian tingkat partisipasi Program Desa Mandiri Pangan (DMP) di Kelurahan Padang Serai Kecamatan Kampung Melayu Kota Bengkulu memiliki rata-rata sebesar 28.13 yang berarti bahwa tingkat partisipasi anggota afinitas (dahlia sejahtera) terhadap Program Desa Mandiri Pangan (DMP) termasuk dalam kategori sedang, hal ini disebabkan karena anggota tidak selalu terlibat dalam kegiatan-kegiatan yang dilaksanakan sehingga manfaat dan keuntungan yang mereka dapatkan tidak begitu optimal. Sebaran partisipasi responden tersebut secara rinci disajikan pada tabel 3 .

Tabel. 2 Tingkat Partisipasi Anggota Kelompok Afinitas

\begin{tabular}{|l|l|l|l|}
\hline No & Kategori tingkat partisipasi (skor) & Rata-rata & Tingkat Partisipasi \\
\hline 1 & Rendah $=14-23,4$ & 28.13 & Sedang \\
2 & Sedang $=23,4-32,7$ & & $23,4-32,7$ \\
3 & Tinggi $=32,7-42$ & & \\
\hline
\end{tabular}

Sumber: Data Primer

Tabel. 3 Distribusi Partisipasi Anggota Kelompok Afinitas

\begin{tabular}{|l|l|l|l|l|l|}
\hline No & Kelas Distribusi & Jumlah (jiwa) & Persen (\%) & Rata-rata & Kisaran \\
\hline 1 & Rendah $=14-23,4$ & 5 & 15.63 & 28.13 & $14-42$ \\
2 & Sedang $=23,4-32,7$ & 21 & 65.63 & & \\
3 & Tinggi $=32,7-42$ & 6 & 18.75 & & \\
\hline & Jumlah & 32 & 100 & & \\
\hline
\end{tabular}

Sumber: Data Primer 
Dari Tabel 3, terlihat bahwa partisipasi responden yang paling banyak adalah kelas antara 23,4 - 32,7 yaitu dengan kategori sedang dengan jumlah 21 orang atau $65.63 \%$. Sedangkan partisipasi responden paling sedikit antara $14-23,4$ yaitu dengan kategori rendah, berjumlah 5 orang responden atau $15,63 \%$. Rata-rata partisipasi responden adalah 28,13 dengan kategori sedang.

\section{Tingkat Persepsi Anggota Afinitas Program Desa Mandiri Pangan}

Persepsi tentang Desa Mandiri Pangan adalah pandangan yang dimiliki seseorang dalam melihat dan memahami manfaat yang diusahakan desa mandiri pangan tersebut bagi usahanya. Persepsi anggota kelompok afinitas (dahlia sejahtera) atas pelayanan, informasi, pengambilan keputusan, tentang pelaksanaan kegiatan program desa mandiri pangan yang baik akan menimbulkan partisipasi anggota itu sendiri. Persepsi anggota dalam pengambilan keputusan dan pelaksanaan kegiatan dalam desa mandiri pangan dapat dikatakan sebagai penilaian atau tanggapan dari anggota kelompok afinitas (dahlia sejahtera) terhadap program desa mandiri pangan tersebut, hal ini dipengaruhi oleh adanya kepentingan, kepribadian dan pengalaman sebelumnya. Tingkat persepsi anggota kelompok afinitas (dahlia sejahtera) terhadap Program Desa Mandiri Pangan (DMP) di Kelurahan Padang Serai Kecamatan Kampung Melayu Kota Bengkulu disajikan pada tabel disajikan pada tabel 4 .

Tabel. 4 Tingkat Persepsi Anggota Afinitas

\begin{tabular}{|l|l|l|l|}
\hline No & $\begin{array}{l}\text { Kategori tingkat persepsi } \\
(\text { skor })\end{array}$ & Rata-rata & Tingkat Persepsi \\
\hline 1 & Rendah $=14-23,4$ & 33,06 & Tinggi \\
2 & Sedang $=23,4-32,7$ & $32,7-42$ \\
3 & Tinggi $=32,7-42$ & & \\
\hline
\end{tabular}

Sumber: Data Primer diolah, 2016 
Persepsi anggota kelompok afinitas (dahlia sejahtera) tentang Program Desa Mandiri Pangan merupakan pandangan seseorang dalam melihat dan memahami hubungan dirinya dengan Program Desa Mandiri Pangan. Dari data yang di dapat persepsi responden berada pada rata-rata 33,06. Kondisi ini menunjukkan bahwa anggota kelompok afinitas (dahlia sejahtera) memiliki persepsi yang tinggi atau baik terhadap Program Desa Mandiri Pangan. Mereka percaya bahwa Program Desa Mandiri Pangan dapat membantu usaha mereka, sehingga produktivitas petani dalam hal ini anggota kelompok afinitas (dahlia sejahtera) menjadi semakin meningkat. Sebaran partisipasi responden tersebut secara rinci disajikan pada Tabel 5.

Dari Tabel 5, terlihat bahwa persepsi responden yang paling banyak adalah kelas antara 32,7-42 yaitu dengan kategori tinggi dengan jumlah 18 orang atau $56,25 \%$. Sedangkan persepsi responden paling sedikit antara $14-23,4$ yaitu dengan kategori rendah, berjumlah 6 orang responden atau $18,75 \%$. Rata-rata partisipasi responden adalah 33,06 dengan kategori tinggi.

Tingginya persepsi petani diartikan bahwa petani memiliki persepsi yang baik terhadap Program Desa Mandiri Pangan, maka petani cenderung untuk melakukan atau mengikuti kegiatan Program Desa Mandiri Pangan. Hal ini dikarenakan petani masih yakin dengan kegiatan Program Desa Mandiri Pangan akan dapat meningkatkan pendapatan keluarganya. Karena persepsi akan dapat melahirkan rangsangan yang baik untuk mengetahui atau untuk melakukan sesuatu yang dapat diperoleh melalui alat indera, fakta atau pengalaman. Dengan persepsi petani akan paham bagaimana proses menyeleksi, mengatur dan menginterpretasikan masukan-masukan informasi desa mandiri pangan untuk menciptakan gambar keseluruhan yang berarti bagi petani dan masyarakat.

\section{Tabel. 5 Distribusi Persepsi Anggota Kelompok Afinitas}

\begin{tabular}{|l|l|l|l|l|l|}
\hline No & Kelas Distribusi & Jumlah (jiwa) & Persen (\%) & Rata-rata & Kisaran \\
\hline 1 & Rendah $=14-23,4$ & 6 & 18,75 & 33,06 & $14-42$ \\
2 & Sedang $=23,4-32,7$ & 8 & 25 & & \\
3 & Tinggi $=32,7-42$ & 18 & 56,25 & & \\
\hline & Jumlah & 32 & 100 & & \\
\hline
\end{tabular}

Sumber: Data Primer 


\section{KESIMPULAN}

Berdasarkan hasil penelitian tingkat partisipasi terhadap Program Desa Mandiri Pangan (DMP) di Kelurahan Padang Serai Kecamatan Kampung Melayu Kota Bengkulu memiliki rata-rata sebesar 28.13 yang berarti bahwa tingkat partisipasi anggota afinitas (dahlia sejahtera) terhadap Program Desa Mandiri Pangan (DMP) termasuk dalam kategori sedang. Partisipasi responden yang paling banyak adalah kelas antara 23,4 - 32,7 yaitu dengan kategori sedang dengan jumlah 21 orang atau $65.63 \%$. Sedangkan partisipasi responden paling sedikit antara 14 - 23,4 yaitu dengan kategori rendah, berjumlah 5 orang responden atau $15,63 \%$.

Dari data yang di dapat persepsi responden berada pada rata-rata 33,06. Kondisi ini menunjukkan bahwa anggota kelompok afinitas (dahlia sejahtera) memiliki persepsi yang tinggi atau baik terhadap Program Desa Mandiri Pangan. Persepsi responden yang paling banyak adalah kelas antara 32,7-42 yaitu dengan kategori tinggi dengan jumlah 18 orang atau 56,25\%. Sedangkan persepsi responden paling sedikit antara $14-23,4$ yaitu dengan kategori rendah, berjumlah 6 orang responden atau $18,75 \%$.

\section{DAFTAR PUSTAKA}

Arikunto, Suharsimi. 2006. Prosedur Penelitian Suatu Pendekatan Praktik. Rineka Cipta. Jakarta.

BKP. 2014. Pedoman Umum Program Aksi Desa Mandiri Pangan. Badan Ketahanan Pangan. Departemen Pertanian.

BKP. 2015. Pedoman Umum Program Aksi Desa Mandiri Pangan. Badan Ketahanan Pangan. Departemen Pertanian.

BPS. 2015. Statistik Indonesia Tahun 2015. Bengkulu : Badan Pusat Statistik.

BPS. 2017. Statistik Indonesia Tahun 2015. Bengkulu : Badan Pusat Statistik.

Darwis, V. dan I W. Rusastra. 2011. Optimalisasi Pemberdayaan Masyarakat Desa Melalui Sinergi Program PUAP Dengan Desa Mandiri Pangan. Analisis Kebijakan Pertanian, 9(2): 125142.

Darwis, Valeriana. 2012. Gerakan Kemandirian Pangan Melalui Program Desa Mandiri Pangan : Analisis Kinerja Dan Kendala: Jurnal Analisis Kebijakan Pertanian. Volume 10 No. 2, Juni 2012.

Deptan. 2012. Pedoman Umum Program Aksi Desa Mandiri Pangan. Badan Ketahanan Pangan. Departemen Pertanian.

Iswantoro. 2006. Situasi Pangan. Penuntun BKP (online) http.binaswadaya.org (diakses tanggal 20.09.2016).

Siegel, 2001. Statistik Non Parametrik Untuk Ilmu-Ilmu Sosial. Gramedia Jakarta. 